\title{
Bilateral postaxial polydactyly with hallux valgus in both feet: report of an adult case
}

\author{
Cong Cheng, Anxiong Liu, Yanggang Ouyang, Hai Liang, Zongyuan Jiang \\ Department of Hand Surgery, Affiliated Longhua People's Hospital, Southern Medical University, Shenzhen, China \\ Correspondence to: Zongyuan Jiang. Affiliated Longhua People's Hospital, Southern Medical University, Shenzhen 518109, China. \\ Email: 13823153297@163.com.
}

Submitted Feb 14, 2020. Accepted for publication Sep 01, 2020.

doi: 10.21037/qims-20-227

View this article at: http://dx.doi.org/10.21037/qims-20-227

\section{Introduction}

Polydactyly of the foot is a rare congenital anomaly, characterized by the presence of additional digit(s), ranging from a rudimentary structure to a completely developed accessory ray. The incidence is reported to be 1.7:1,000 in live births (1). Postaxial polydactyly is defined as a complete or partial supernumerary digit on the lateral aspect of the foot (2). Hallux valgus (HV) is a forefoot deformity of the first ray, characterized by an abduction of the first metatarsophalangeal joint (MTPJ) accompanied with lateral deviation of the great toe and medial deviation of the first metatarsal (3). The general consensus is that $\mathrm{HV}$ is more of a developmental or acquired condition, having nothing to do with congenital postaxial polydactyly. Bilateral postaxial polydactyly is not infrequent when coupled with genetic syndromes such as Ellis-van Creveld syndrome and oral-facial-digital syndrome; however, isolated cases of bilateral postaxial polydactyly along with acquired HV in both feet are extremely rare. Surgical treatment of these malformations is very challenging; there is no existing report on this topic as a point of reference. Here, we have reported on such a case, along with its surgical treatment.

\section{Case presentation}

A 22-year-old female was admitted to Affiliated Longhua People's Hospital, Southern Medical University with bilateral foot postaxial polydactyly and HV deformity. She was born with a lateral sixth toe without HV. She presented with no other systemic anomalies and no relevant family history. She had postponed consultation until adult life, when progressive HV become manifest. Her main complaint was bilateral forefoot pain, difficulty wearing normal shoes, and an abnormal cosmetic appearance.

Physical examination revealed fully developed extra toes that appeared to arise from the fifth metatarsal of each foot. She also displayed bilateral moderate HV deformity with an overlap of the second toe on the great toe (Figure 1). The radiograph revealed complete bilateral duplication of the phalanges arising from the fifth metatarsal head. The patients' metatarsal bones showed an incomplete form of polymetatarsia, with a T-shaped metatarsal head in the left foot and a Y-shaped metatarsal head in the right foot. Moreover, the left foot showed an intermetatarsal angle (IMA) of $14^{\circ}$ and a hallux valgus angle (HVA) of $43^{\circ}$. The right foot showed an IMA of $10^{\circ}$ and an HVA of $29^{\circ}$ (Figure 2).

The patient was placed in a supine position and underwent spinal anesthesia. Both lower limbs were prepared and draped. A racquet-shaped incision was made over the fifth intermetatarsal web space, and then the fifth toe was excised completely. A preplanned osteotomy of the fifth metatarsal medial head was performed with a micro-sagittal oscillating saw to adjust the toe into normal alignment (see template on Figure 3). Next, internal fixation with a plate and screws was performed on the fifth metatarsal. The soft tissue attachments were repaired in layers, and a Kirschner wire was used to stabilize the MTPJ. To address the HV, a medial longitudinal incision was made from the base of the proximal phalanx, extending 3-4 cm proximally to the first tarsometatarsal joint. After dissecting the subcutaneous tissue and bursa, the medial joint capsule was identified. Bunionectomy was then performed by 


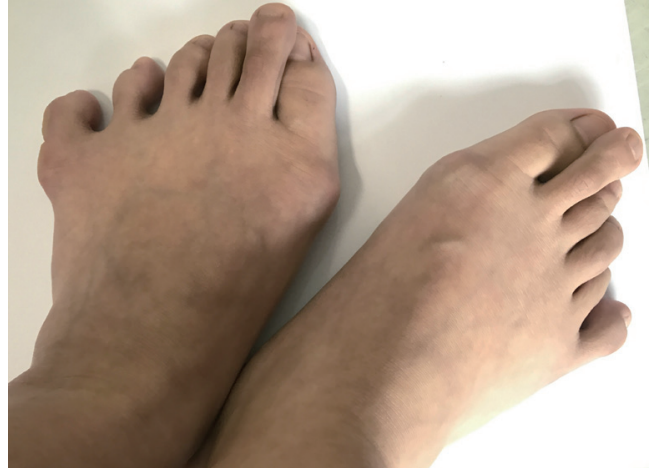

Figure 1 Preoperative clinical photograph of both feet.

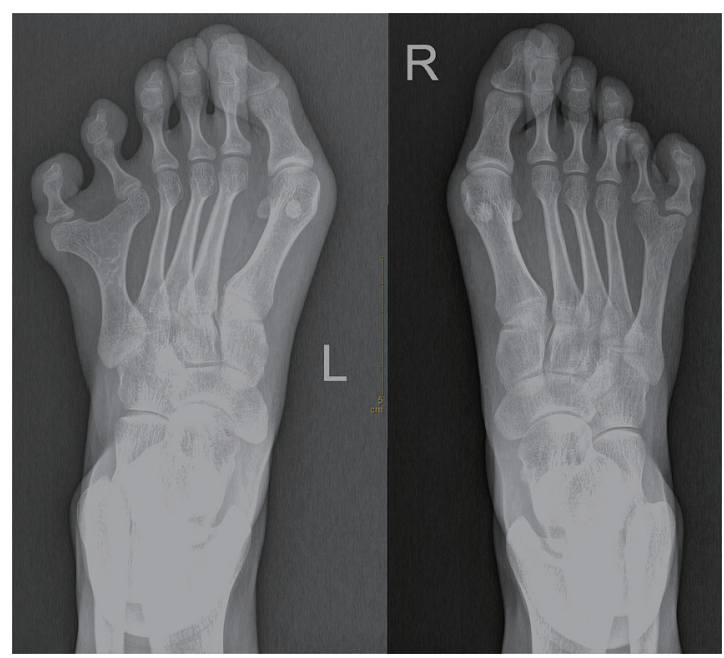

Figure 2 Preoperative radiograph of both feet.

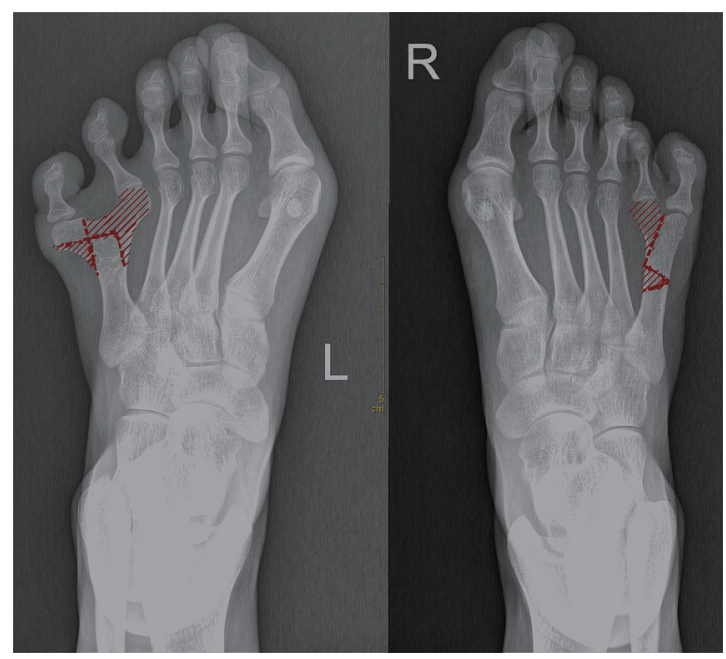

Figure 3 Preplanned osteotomy of both feet before surgery. The hatched section is the resected part of the metatarsal head. sawing just medial to the sulcus. A distal chevron osteotomy was conducted on the head of the first metatarsal, and the capital fragment was shifted laterally by $3-4 \mathrm{~mm}$; the osteotomy site was then fixed with two $1.2 \mathrm{~mm}$ Kirschner wires. Prominent bone edges were excised with the saw, and a $3 \mathrm{~cm}$ dorsal longitudinal incision was made in the space of the first intermetatarsal web. The adductor hallucis tendon was detached from its insertion at the phalangeal bone. In the end, these incisions were closed without modification.

The patient was discharged from hospital on the eighth day. Follow-up radiographs were taken at 6 (Figure 4) and 12 months (Figure 5) postoperatively, and both showed a normal metatarsal configuration with satisfactory alignment of the first ray. Physical examination at 12 months after surgery showed excellent cosmetic correction. The patient was pain-free during activity, and was also able to wear normal shoes (Figure 6).

\section{Discussion}

Congenital HV is an uncommon deformity. The intrinsic factors such as a long first metatarsal, a wide metatarsal head, and soft tissue weakness of the MTPJ are thought to be associated with the development of acquired HV. Abnormal forefoot loading caused by narrow toe-box shoes and high heels can exacerbate the deformity (4). Belthur et al. reported that in preaxial polydactyly patients, there was a marked tendency for persistent HV at follow-up (5). Thus far, however, no relevant studies have reported on the correlation between acquired $\mathrm{HV}$ and postaxial polydactyly. A wide forefoot associated with postaxial polydactyly and abnormal forefoot loading in the case of this female patient were potentially the combined cause that resulted in the formation and progression of HV. Evidence has shown that surgical intervention to correct $\mathrm{HV}$ deformity is more effective than conservative treatment, as it appears to improve health-related quality of life (6). Over the years, there have been more than 130 surgical procedures successfully carried out around the world. For surgical correction of mild-to-moderate deformity, distal chevron osteotomy is widely accepted and recommended. The advantages of this surgery are the simplicity of the operation, the reliable stability of the osteotomy, and rapid healing. A potential disadvantage is avascular necrosis of the first metatarsal head (7). At follow-up, the participant had no avascular necrosis of the first metatarsal head or recurrence of deformity. 


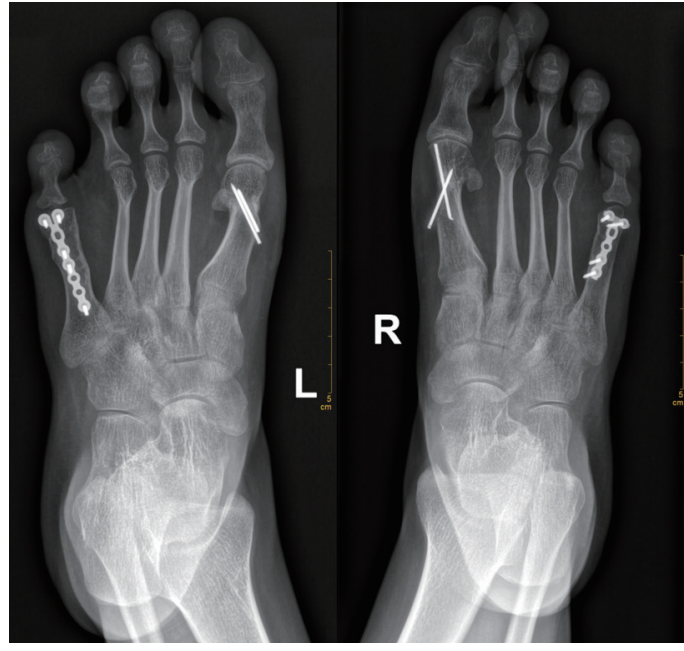

Figure 4 Postoperative radiograph of both feet at 6 months after surgery.

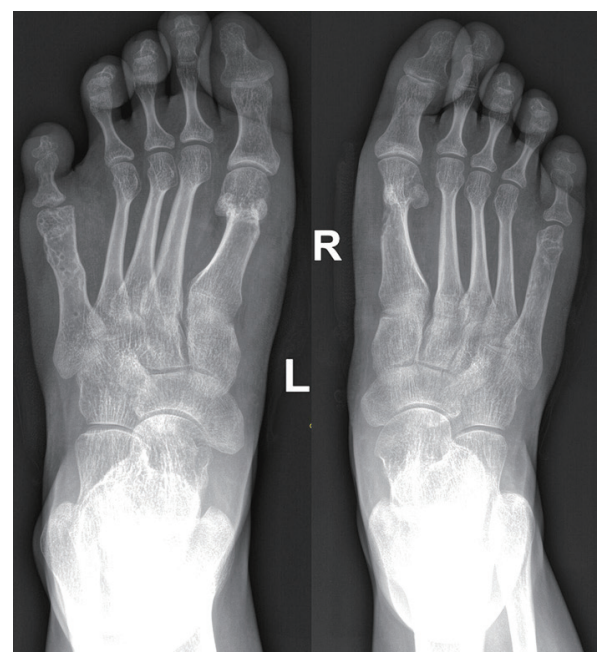

Figure 5 Postoperative radiograph of both feet at 12 months after surgery.

In regard to the timing of surgery for foot polydactyly, Kubat $e t$ al., from a study. of 16 postaxial and 8 preaxial cases, suggested that surgical timing does not influence the final result of treatment, asserting that judicious selection of surgical treatment is the key to success (8). Surgical excision of the extra digit, with reconstruction, has been the predominant treatment for restoring normal or nearnormal foot structure and function. However, metatarsal management is challenging as it varies between cases, according to the surgeons' preference and patients' physical

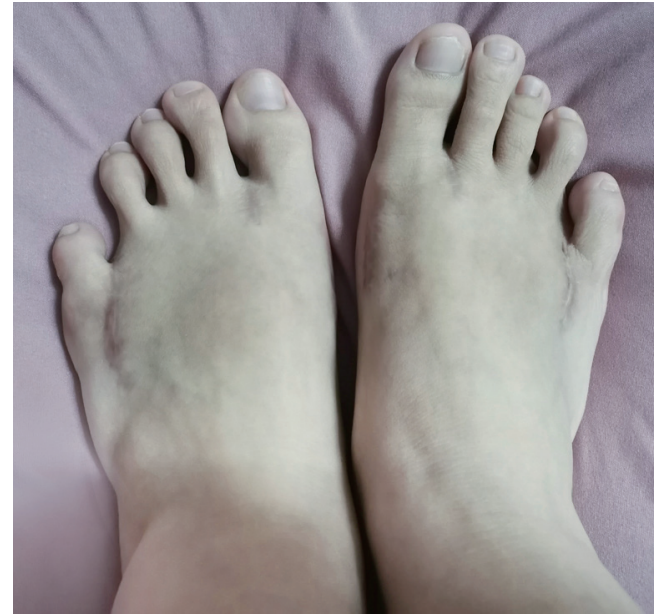

Figure 6 Postoperative clinical photograph of both feet at 12 months after surgery.

presentation (9). In our case, a Y-shaped and T-shaped metatarsal were present in each foot. In order to achieve optimal alignment of the first ray, the deformed metatarsal heads were partly excised, transferred, and trimmed to be flush with the shaft and congruous with the preplanned osteotomy. Moreover, internal fixation with plates and screws was performed to maintain a typical metatarsal configuration.

Selection of which duplicated toe (medial or lateral) should be excised requires an individualized assessment. Many factors, such as circulation, site of origin, presence of hypoplasia, state of fusion, axial alignment, and overall cosmesis must be taken into consideration. The excision of an outer toe is technically relatively simple, but a lingering conspicuous scar may result on the lateral side and lead to adduction deformity of the remaining inner toe. The inner toe has generally been considered the more hypoplastic one, and it is simpler to conceal the surgical scar after its excision. However, this may result in abduction deformity of the remaining outer toe (10). Phelps et al. suggested that if the inner and outer toes were both fully developed, the inner toe should be excised in spite of the resultant residual widening of the forefoot (2). In our case, we excised the fully formed inner toe. To maintain full range of motion, the collateral ligaments and MTPJ capsules were repaired. Then, the intermetatarsal ligament was reapproximated to support the lateral longitudinal arch of the foot. Additionally, the abductor digiti quinti was reinserted with adequate tension to achieve a balanced digit. Furthermore, 
percutaneous fixation with a Kirschner wire was performed to reinforce the stability of the MTPJ.

In conclusion, this case presentation has demonstrated that postaxial polydactyly can be a potential cause of HV. Physical examination and radiologic evaluation are important to determine the most accurate surgical procedure for each case. Surgeons should be aware of this unusual malformation and that surgical treatment must be tailored to the individual patient in regard to both functional and aesthetic considerations.

\section{Acknowledgments}

Funding: None.

\section{Footnote}

Conflicts of Interest: All authors have completed the ICMJE uniform disclosure form (available at http://dx.doi. org/10.21037/qims-20-227). The authors have no conflicts of interest to declare.

Open Access Statement: This is an Open Access article distributed in accordance with the Creative Commons Attribution-NonCommercial-NoDerivs 4.0 International License (CC BY-NC-ND 4.0), which permits the noncommercial replication and distribution of the article with the strict proviso that no changes or edits are made and the original work is properly cited (including links to both the formal publication through the relevant DOI and the license). See: https://creativecommons.org/licenses/by-nc$\mathrm{nd} / 4.0 /$.

Cite this article as: Cheng C, Liu A, Ouyang Y, Liang H, Jiang Z. Bilateral postaxial polydactyly with hallux valgus in both feet: report of an adult case. Quant Imaging Med Surg 2021;11(2):858-861. doi: 10.21037/qims-20-227

\section{References}

1. Zhou GX, Dai L, Zhu J, Miao L, Wang YP, Liang J, Wu YQ. Epidemiological analysis of polydactylies in Chinese perinatals. Sichuan Da Xue Xue Bao Yi Xue Ban 2004;35:708-10.

2. Phelps DA, Grogan DP. Polydactyly of the foot. J Pediatr Orthop 1985;5:446-51.

3. Coughlin MJ, Jones CP, Viladot R, Golanó P, Grebing BR, Kennedy MJ, Shurnas PS, Alvarez F. Hallux Valgus and First Ray Mobility. Foot Ankle Int 2004;25:537-44.

4. Coughlin MJ, Jones CP. Hallux Valgus: Demographics, Etiology, and Radiographic Assessment. Foot Ankle Int 2007;28:759-77.

5. Belthur MV, Linton JL, Barnes DA. The spectrum of preaxial polydactyly of the foot. J Pediatr Orthop 2011;31:435-47.

6. Torkki M, Malmivaara A, Seitsalo S, Hoikka V, Laippala P, Paavolainen P. Surgery vs orthosis vs watchful waiting for hallux valgus: a randomized controlled trial. JAMA 2001;285:2474-80.

7. Klugarova J, Hood V, Bath-Hextall F, Klugar M, Mareckova J, Kelnarova Z. Effectiveness of surgery for adults with hallux valgus deformity: a systematic review. JBI Database System Rev Implement Rep 2017;15:1671-710.

8. Kubat $\mathrm{O}$, Antičević $\mathrm{D}$. Does timing of surgery influence the long-term results of foot polydactyly treatment? Foot Ankle Surg 2018;24:353-8.

9. Morley SE, Smith PJ. Polydactyly of the feet in children: suggestions for surgical management. Br J Plast Surg 2001;54:34-8.

10. Lee HS, Park SS, Yoon JO, Kim JS, Youm YS. Classification of postaxial polydactyly of the foot. Foot Ankle Int 2006;27:356-62. 